\title{
Effect of Sensor Failure on Emission Standards for Petrol \& Diesel Engine
}

\author{
Visranth Jeyakhar M R P, Vignesh S, Prathoshver S, C. Pradeepkumar, Karthikeyan S
}

\begin{abstract}
The study of sensor failure and its effect on emission standard on petrol and diesel engine using five gas analyzer and KTS 570 is presented in this article. The sensor failure is checked with the help of ESI[Tronic] a software-based application helps to scan the whole sensor data of vehicle. The gas analyzer used has an ability to scan about five gases namely $\mathrm{CO}, \mathrm{CO} 2, \mathrm{HC} \mathrm{NOX}, \mathrm{O}_{2}$ these are the main gases that can be easily scanned by analyzer. Along with those emissions standard ESI[Tronic] data were parallel monitored for the uniformity of engine running. This work presents the comparative study of $B S$ III and BS IV engine behavior on sensor failure. The emission data were plotted and compared with each other for three different make.
\end{abstract}

Keywords: ESI[Tronic], Sensor Testing, On-board Diagonastics $(O B D)$

\section{INTRODUCTION}

$\mathrm{P}$ rofessional repair and maintenance of vehicles requires access to industry programs containing technical data necessary in the repair process. The BOSCH company offers comprehensive technical documentation, with the option of selecting modules containing information on a specific subject, such as vehicle equipment, mechanical repairs, electrical diagrams, etc. This allows the software range to be adapted to the actual needs of the services and the most frequently performed repairs.

The major problems that identified through the ESI Tronic is follows below. Effect of sensor failure in BS III and BS IV emission norms engines leads to error signals in vehicles, very few researchers address this issue in the literatures. Mass Air Flow sensor failure and the related emission issues in recent BS III and BS IV engines were not addressed properly. Comparative study on Petrol and Diesel engine on sensor failures also not addresses extensively. The

Revised Manuscript Received on December 05, 2019.

* Karthikeyan S

Visranth Jeyakhar M R P*, Department of Automobile Engineering, Kalasalingam Academy of Research and Education, Krishnankoil, Virudhungar, Tamilnadu, India - 626126. Email: visranth27@ gmail.com

Vignesh S, Department of Automobile Engineering, Kalasalingam Academy of Research and Education, Krishnankoil, Virudhungar, Tamilnadu, India - 626126. Email: vicky329889@gmail.com

Prathoshver S, Department of Automobile Engineering, Kalasalingam Academy of Research and Education, Krishnankoil, Virudhungar, Tamilnadu, India - 626126. Email: 9915010045@klu.ac.in

C. Pradeepkumar, Department of Automobile Engineering, Kalasalingam Academy of Research and Education, Krishnankoil, Virudhungar, Tamilnadu, India - 626126. Email: pradeep93smart@gmail.com

Karthikeyan S, Department of Automobile Engineering, Kalasalingam Academy of Research and Education, Krishnankoil, Virudhungar, Tamilnadu, India - 626126. Email: skarthikeyan@klu.ac.in objective of this work is to Compare the engine performance affecting parameters of BS III and BS IV engines type of same make. Compare the engine performance affecting parameters of BS III and BS IV engines type of same make. Study of sensor failures and the related engine performance effect. Solutions to avoid the drop-in engine performance due to sensor failures. Comparative study of petrol and diesel engine emission standard over sensor failure.

Baldean et al [1] formalised an innovative method for fuel consumption in diesel engine with electronic control module. Optimizing the fuel consumption and engine thermal efficiency, as well as the reduction of friction forces due to a better lubrication is a desirable goal. Stanly et al [2] studied the influence of injector choking deposits. The influence of injector deposits on vehicular performance and spray field were analysed and removal of coking deposits increased the overall efficiency of the engine. Baldean et al [3] studied the features from Euro $\mathrm{V}$ diesel engine management in relation with fuel consumption and different driving road conditions and the values displayed On Board Diagnosis screens. Sumorek et al [4] performed the practical tests in the scope of on-board diagnostics for "premium" class vehicle and diagnostics functions. They discussed about the introduction of systems for the monitoring of vehicle sub- assemblies contributing to emission levels in all vehicles the necessity to use the basic functions of on-board diagnostics (OBD) in all the motor vehicles and similar tests were carried out by means of 4 diagnostic interfaces. Olszowski et al [5] insinuated the methods of diagnosis which are wider than systems of control in the process of self-diagnosis have been prepared and discussed. Nekitsingh et al [6] investigated and studied the benefits and impact of using the environmentally friendly HC-12a refrigerant in car air conditioning as a drop-in replacement for the hydrofluorocarbon refrigerant, R134a. Adamiec et al [7] performed the tests to register signals that have a direct impact on the ABS system when braking and accelerating the vehicle. The purpose of the simulation tests was to analyse the influence of signals from the velocity sensors of individual wheels and the moment of recognition of the fault signalled by the ABS diagnostic lamp lighting From all the above literature very, few researchers address the effect of sensor failures on the emission standards, so the current study focus mainly on the sensor failures particularly on Mass air flow sensor and its related effects. This study also compares the effect on BS III and BS IV standard vehicle. 


\section{TEST PROCEDURE}

\section{A. Sensor Check}

The study of sensor failure and effect on the emission of vehicle on both BS III and BS IV. There are several tests handled to know that the sensor failure in the vehicle. One of the major tests taken to know the sensor failure is on board diagnosis the BOSCH has designed a special device to check the sensor failure known to be ESI [TRONIC] it's a software-based program that is connected with vehicle using the device called KTS 570. The device is connected with general OBD port present inside the car the test is taken as follows:

The car is connected to the OBD port.

Then the device is connected to the laptop where the ESI[TRONIC] software is previously installed.

Then the engine is on idling condition.

Then run fault memory diagnosis.

After that the actual data is selected.

And the tests are taken in runtime of engine.

After that the mass air flow sensor is manually removed and then the engine is checked under running condition.

\section{B. Emission Test}

The emission test is taken using five gas analyzers, it is important to observe all the gas emitted by vehicles. There are procedures to be followed to take test to avoid cautions created due to smoke the steps are as follows:

- The vehicle is settled at proper ventilated area

- Then the five-gas analyser is started (it takes some time to start the suction)

- The suction tube is cleaned with air pump and then fitted with the analyser

- The suction tube is placed in the exhaust of the car

- Then the values are noted with different RPM

- The values of gases are observed and graph is plotted

After the test is done the step explained above will be repeated with different cars to find the emission at different RPM. The data would help to find how the emission varies with MAF sensor and without MAF sensor. The above is followed far all cars with different made.

Here the graph explains the emission of carbon monoxide (CO), carbon dioxide $\left(\mathrm{CO}_{2}\right)$, nitrogen oxide (NOX), hydrocarbon (HC) in both BS III and BS IV. It is completely zero when the MAF sensor is connected and then there is huge change in emission of vehicle when the MAF is removed manually. some of the car tested in different condition. The data given in the given next chapter is used to plot the graph to observe the difference of variation of emission of presence and absence of MAF sensor.

\section{RESULTS AND DISCUSSION}

\section{A. Ford Eco Sport - BS III}

The first model chosen for the study is FORD - EcoSport (2015) used to analyse the effect. The BS III model and BS IV model were taken and connected with ESI[Tronic] device and the airflow rate and the load values are monitored for the study. The five-gas analyser is used to analyse the emission gases like $\mathrm{CO}, \mathrm{CO}_{2}, \mathrm{O}_{2}, \mathrm{HC}$ and $\mathrm{NOx}$.

\section{B. Ford Eco Sport - BS IV}

The first model chosen for the study is FORD - EcoSport (2019) used to analyse the effect. The BS III model and BS IV model were taken and connected with ESI-Tronic device and the airflow rate and the load values are monitored for the study. The five-gas analyser is used to analyse the emission gases like $\mathrm{CO}, \mathrm{CO}_{2}, \mathrm{O}_{2}, \mathrm{HC}$ and $\mathrm{NOx}$.

The "Fig. 1" graph plotted below will explains the emission and also the data collected through ESI[Tronic]. The graph shows the amount of gases emitted by ford EcoSport with different norms, here we take BS 3 norms and BS 4 norm engine to know the detail about how emission varies within both the engine. When the MAF is disconnected the ESI[Tronic] show the actual data of MAF as zero in system.

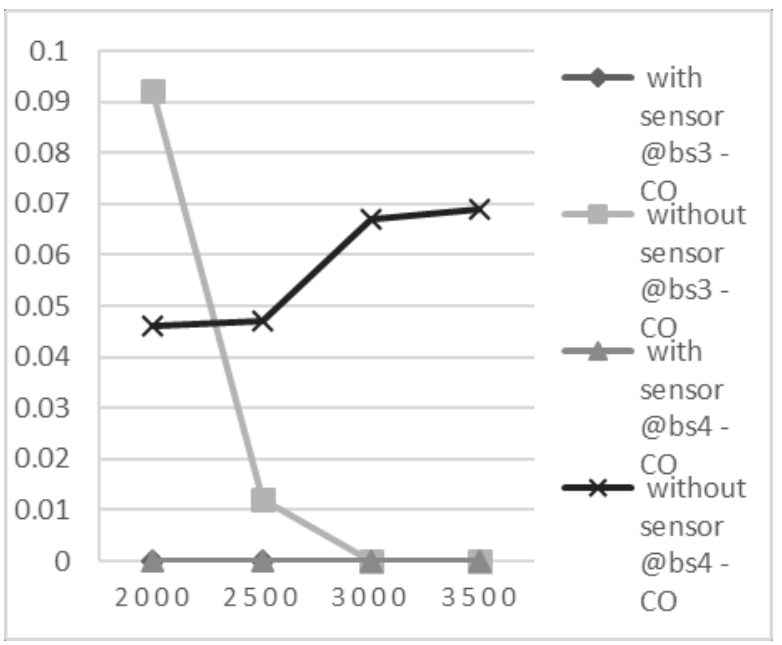

Fig. 1. Emission of $\mathrm{CO}$ under the condition of with and without MAF sensor

This "Fig. 2" shows the amount of CO emitted in different RPM under the condition of MAF sensor connected and not connected, Carbon monoxide is a by- product of combustion, present whenever fuel is burned. During the connection of MAF the value of CO is completely zero and after the removal of MAF sensor the percentage of $\mathrm{CO}$ will increase up to $0.004 \%$ to $0.090 \%$.

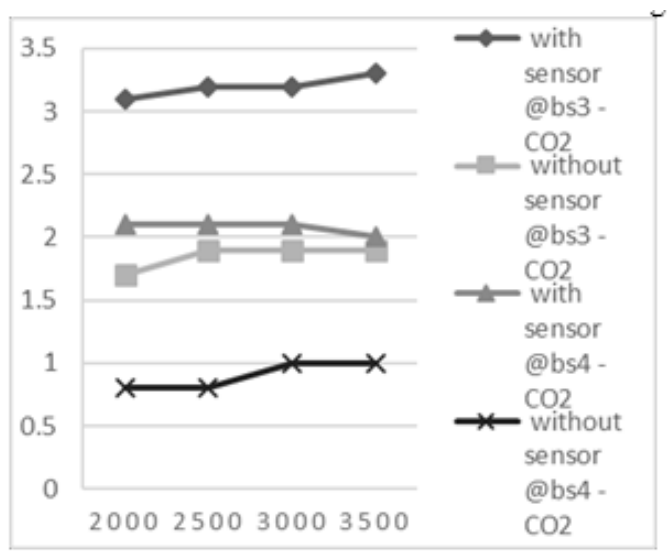

Fig. 2. Emission of $\mathrm{CO}_{2}$ under the condition of with and without MAF Sensor.

The formation of is due burning of fuel in the combustion chamber and lack 
of oxygen. It also formed due to incomplete combustion. It harms human by reducing oxygen carrying capacity of blood. It is also known to be toxic gases.

This "Fig. 2" shows the amount of $\mathrm{CO}_{2}$ emitted in different RPM under the condition of MAF sensor connected and not connected, carbon dioxide is formed from carbon monoxide during combustion. During the connection of MAF the percentage of $\mathrm{CO}_{2}$ may reduce below 2.00. The $\mathrm{CO}$ is

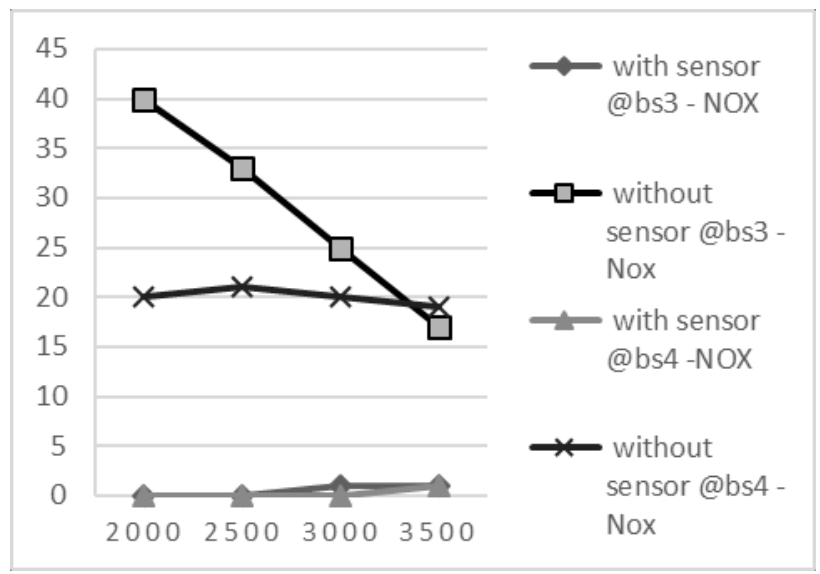

Fig. 3. Emission of NOx under the condition of with and without MAF sensor

The "Fig. 3" shows the amount of NOX emitted during combustion. The NOX is the mixture of Nitrogen, Oxygen, and high enough temperatures. NOx emissions increase with higher combustion temperatures and lean mixture operation, which is when enough unreacted oxygen is present in the exhaust. The level of NOX is about $0 \%$ to $3 \%$ under the condition of MAF connection and it increased up to $30 \%$ to $50 \%$ in absence of MAF

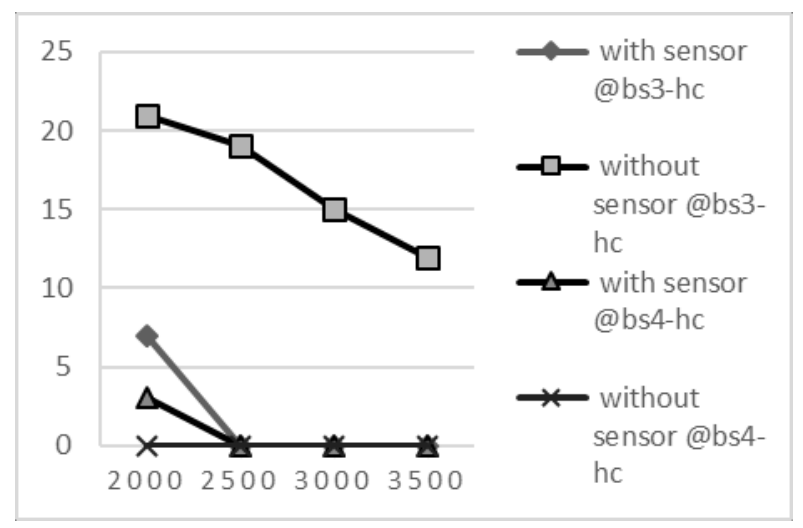

Fig. 4. Emission of $\mathrm{HC}$ under the condition of with and without MAF sensor

This "Fig. 4" shows the amount of HC emitted in different RPM under the condition of MAF sensor connected and not connected, Hydro carbon is a by-product due to homogeneous mixture of air and fuel mixture, present whenever fuel is burned. During the connection of MAF the value of $\mathrm{HC}$ is completely zero and after the removal of MAF sensor the value of HC may increase up to 0 to 25 $\mathrm{ppm}$. The unit for hydro carbon is observed by ppm. the value of $\mathrm{CO}_{2}$ from 0.20 to 4.0 and removal of MAF sensor converted into $\mathrm{CO}_{2}$ in lack of oxygen.

\section{Hyundai $X$ cent BS III}

The first model chosen for the study is Hyundai X cent (2016) used to analyse the effect. The BS III model and BS IV model were taken and connected with ESI[Tronic] device and the airflow rate and the load values are monitored for the study. The five-gas analyser is used to analyse the emission gases like $\mathrm{CO}, \mathrm{CO}_{2}, \mathrm{O}_{2}, \mathrm{HC}$ and $\mathrm{NOx}$.

\section{Hyundai $X$ cent BS IV}

The first model chosen for the study is Hyundai X cent (2017) used to analyse the effect. The BS III model and BS IV model were taken and connected with ESI[Tronic] device and the airflow rate and the load values are monitored for the study. The five-gas analyser is used to analyse the emission gases like $\mathrm{CO}, \mathrm{CO}_{2}, \mathrm{O}_{2}, \mathrm{HC}$ and $\mathrm{NOx}$.

The graph shows the amount of gases emitted by Hyundai X cent with different norms, here we take BS III norms and BS IV norm engine to know the detail about how emission varies within both the engine. When the MAF is disconnected the ESI[Tronic] show the actual data of MAF as zero in system

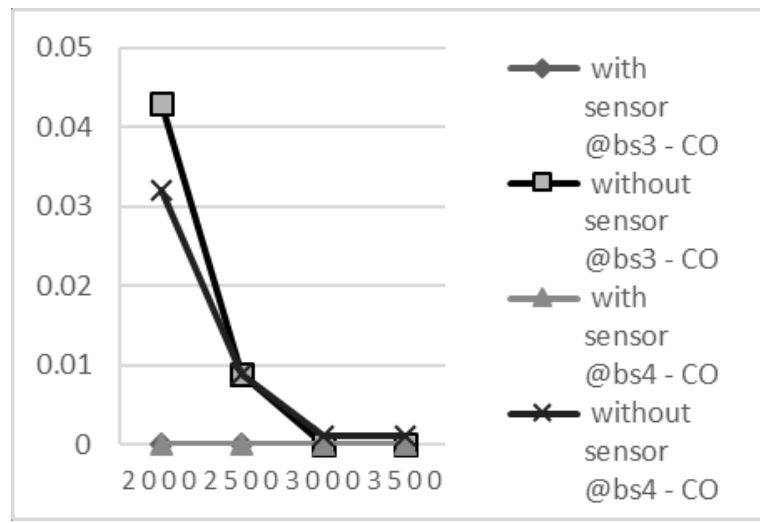

Fig. 5. Emission of $\mathrm{CO}$ under the condition of with and without MAF sensor

This "Fig. 5" shows the amount of CO emitted in different RPM under the condition of MAF sensor connected and not connected, Carbon monoxide is a byproduct of combustion, present whenever fuel is burned. During the connection of MAF the value of $\mathrm{CO}$ is completely zero and after the removal of MAF sensor the percentage of CO will increase up to $0.004 \%$ to $0.090 \%$.

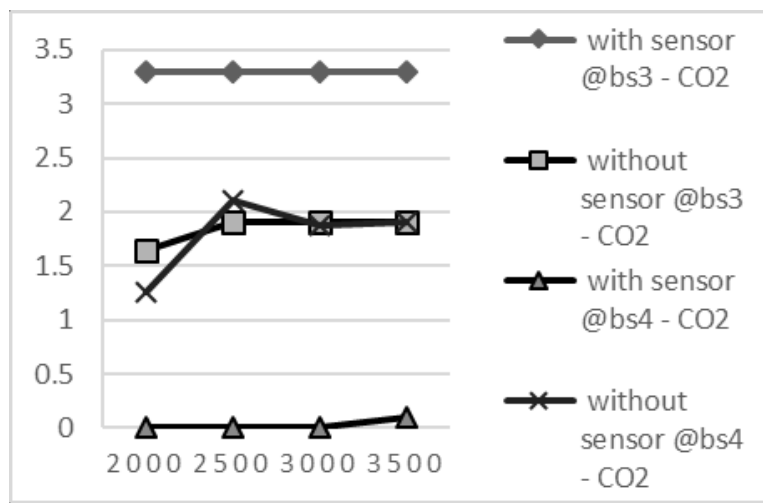

Fig.6. Emission of $\mathrm{CO}_{2}$ under the condition of with and without MAF sensor

This "Fig. 6" shows the amount of $\mathrm{CO}_{2}$ emitted in 
different RPM under the condition of MAF sensor connected and not connected, Carbon dioxide is formed from carbon monoxide during combustion. During the connection of MAF the value of $\mathrm{CO}_{2}$ from 0.20 to 4.0 and after the removal of MAF sensor the percentage of $\mathrm{CO}_{2}$ may reduce below 2.00. The $\mathrm{CO}$ is converted into $\mathrm{CO}_{2}$ in lack of oxygen.

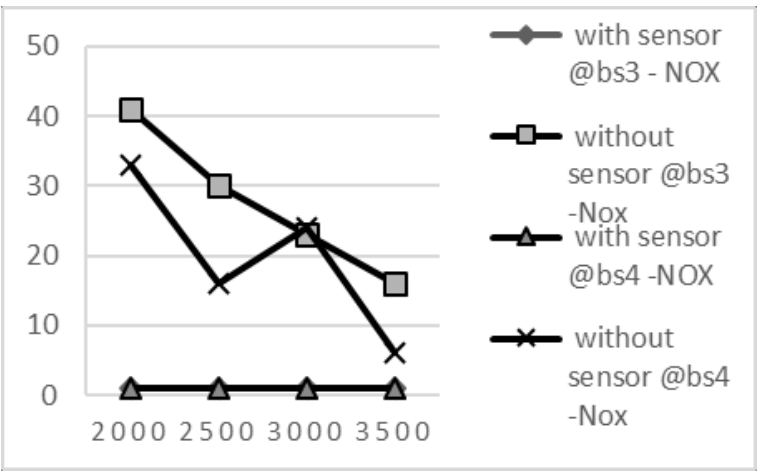

Fig 7: Emission of NOx under the condition of with and without MAF sensor

The "Fig. 7" shows the amount of NOX emitted during combustion. The NOX is the mixture of Nitrogen, Oxygen, and high enough temperatures. NOx emissions increase with higher combustion temperatures and lean mixture operation, which is when enough unreacted oxygen is present in the exhaust. The level of NOX is about $0 \%$ to

$3 \%$ under the condition of MAF connection and it increased up to $30 \%$ to $50 \%$ in absence of MAF.

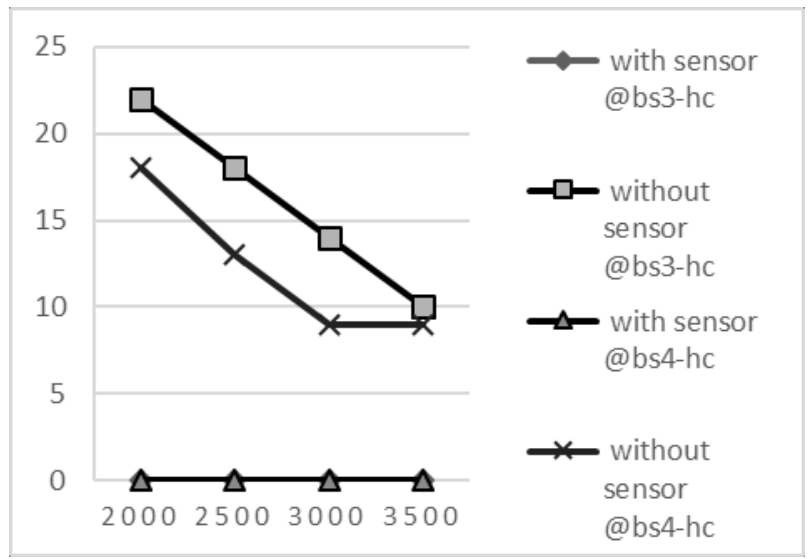

Fig 8: Emission of HC under the condition of with and without MAF sensor

This "Fig. 8" shows the amount of HC emitted in different RPM under the condition of MAF sensor connected and not connected, Hydro carbon is a byproduct due to homogeneous mixture of air and fuel mixture, present whenever fuel is burned. During the connection of MAF the value of $\mathrm{HC}$ is completely zero and after the removal of MAF sensor the value of $\mathrm{HC}$ may increase up to 0 to 25 ppm. The unit for hydro carbon is observed by ppm.

\section{E. Suzuki Baleno BS III}

The first model chosen for the study is Suzuki baleno (2016) used to analyse the effect. The BS III model and BS IV model were taken and connected with ESI[Tronic] device and the airflow rate and the load values are monitored for the study. The five-gas analyser is used to analyse the emission gases like $\mathrm{CO}, \mathrm{CO}_{2}, \mathrm{O}_{2}, \mathrm{HC}$ and NOx.

\section{F. Suzuki Baleno BS IV}

The first model chosen for the study is Suzuki baleno (2019) used to analyse the effect. The BS III model and BS IV model were taken and connected with ESI[Tronic] device and the airflow rate and the load values are monitored for the study. The five-gas analyser is used to analyse the emission gases like $\mathrm{CO}, \mathrm{CO}_{2}, \mathrm{O}_{2}, \mathrm{HC}$ and $\mathrm{NOx}$.

The above data used to plot graph of the emission and also the data collected through ESI[Tronic]. The graph shows the amount of gases emitted by Suzuki baleno with different norms, here we take BS III norms and BS IV norm engine to know the detail about how emission varies within both the engine. When the MAF is disconnected the ESI[Tronic] show the actual data of MAF as zero in system.

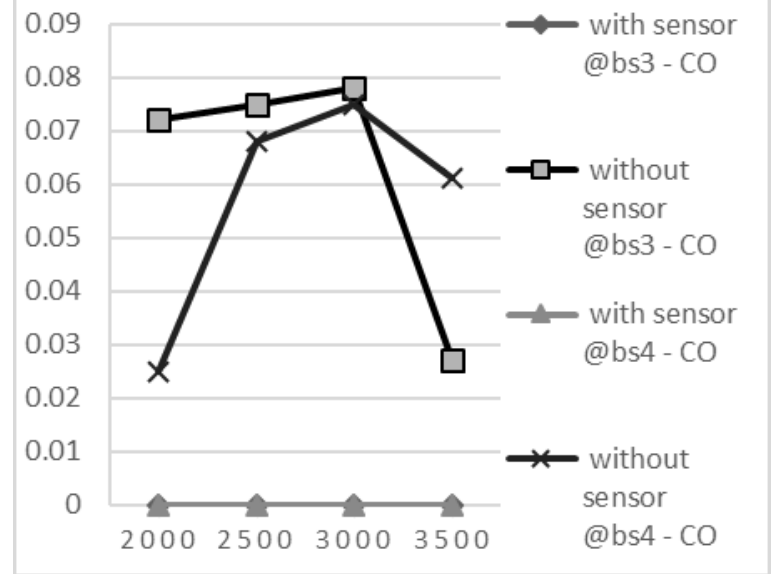

Fig 9: Emission of $\mathrm{CO}$ under the condition of with and without MAF sensor

This "Fig. 9" shows the amount of CO emitted in different RPM under the condition of MAF sensor connected and not connected, Carbon monoxide is a byproduct of combustion, present whenever fuel is burned. During the connection of MAF the value of $\mathrm{CO}$ is completely zero and after the removal of MAF sensor the percentage of $\mathrm{CO}$ will increase up to $0.004 \%$ to $0.090 \%$.
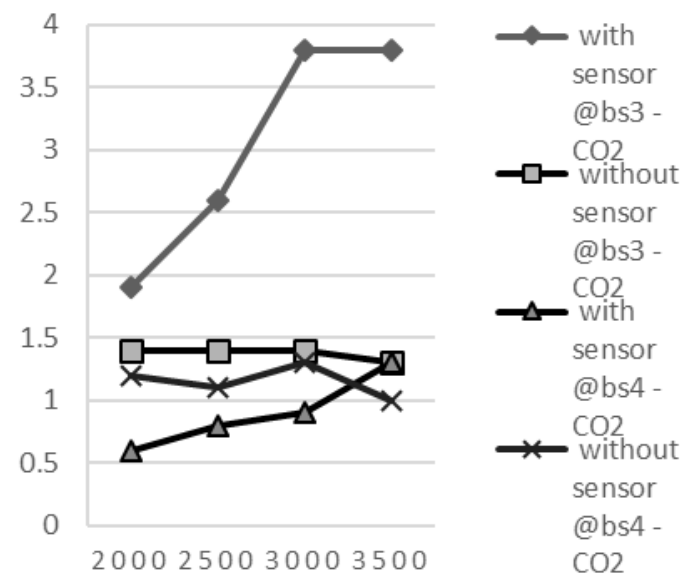

Fig 10: Emission of $\mathrm{CO}_{2}$ under the condition of with and without MAF sensor

This "Fig. 10" shows the amount of $\mathrm{CO}_{2}$ emitted in different RPM under the condition of MAF sensor connected and not connected, carbon dioxide is formed from carbon monoxide during the combustion. During the connection of MAF the value of $\mathrm{CO}_{2}$ from 0.20 to 4.0 and

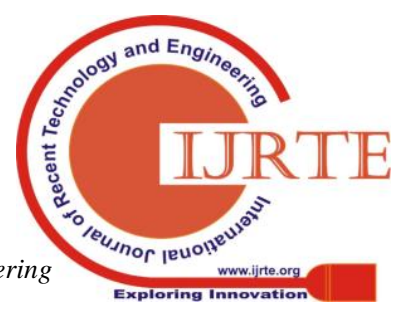


after the removal of MAF sensor the percentage of $\mathrm{CO}_{2}$ may reduce below 2.00. The $\mathrm{CO}$ is converted into $\mathrm{CO}_{2}$ in lack of oxygen.

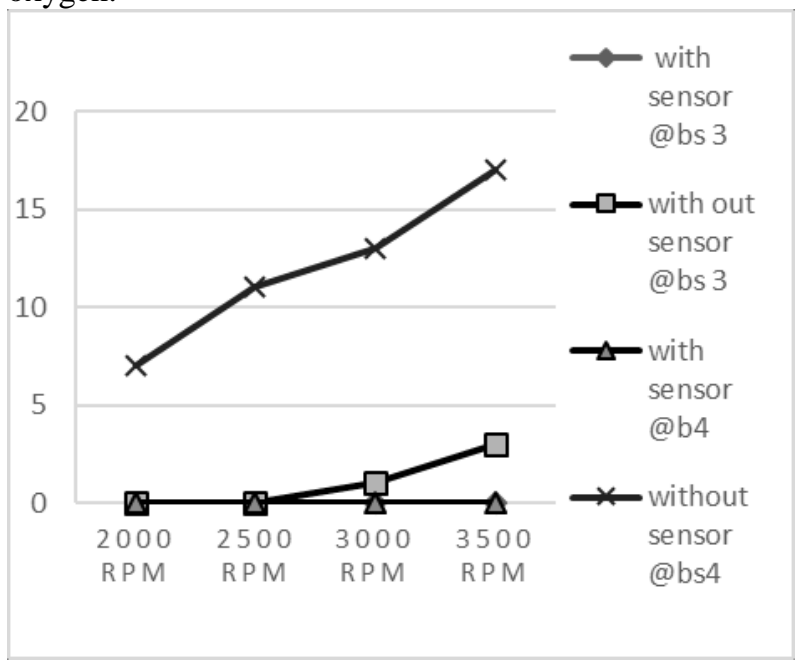

Fig 11: Emission of HC under the condition of with and without MAF sensor

This "Fig. 11" shows the amount of HC emitted in different RPM under the condition of MAF sensor connected and not connected, Hydro carbon is a byproduct due to homogeneous mixture of air and fuel mixture, present whenever fuel is burned. During the connection of MAF the value of $\mathrm{HC}$ is completely zero and after the removal of ppm. The unit for hydro carbon is observed by ppm.

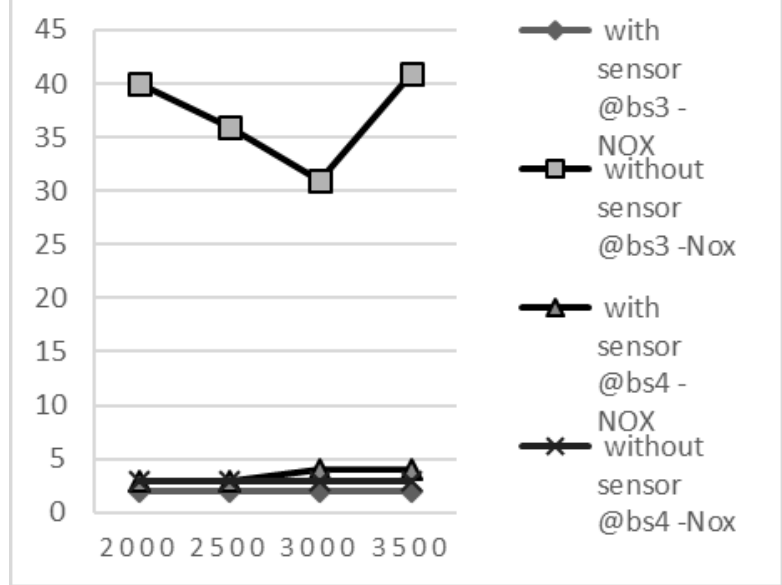

Fig 12: Emission of NOx under the condition of with and without MAF sensor

The "Fig. 12" shows the amount of NOX emitted during combustion. The NOX is the mixture of Nitrogen, Oxygen, and high enough temperatures. NOx emissions increase with higher combustion temperatures and lean mixture operation, which is when enough unreacted oxygen is present in the exhaust. The level of NOX is about $0 \%$ to $3 \%$ under the condition of MAF connection and it increased up to $30 \%$ to $50 \%$ in absence of MAF

\section{G. Suzuki Swift BS III}

The first model chosen for the study is Suzuki swift (2015) used to analyze the effect. The BS III model and BS IV model were taken and connected with ESI[Tronic] device and the airflow rate and the load values are monitored for the study. The five-gas analyzer is used to analyze the emission gases like $\mathrm{CO}, \mathrm{CO}_{2}, \mathrm{O}_{2}, \mathrm{HC}$ and $\mathrm{NOx}$. MAF sensor the value of $\mathrm{HC}$ may increase up to 0 to 25

\section{H. Suzuki Swift BS IV}

The first model chosen for the study is Suzuki Swift (2017) used to analyze the effect. The BS III model and BS IV model were taken and connected with ESI[Tronic] device and the airflow rate and the load values are monitored for the study. The five-gas analyzer is used to analyze the emission gases like $\mathrm{CO}, \mathrm{CO}_{2}, \mathrm{O}_{2}, \mathrm{HC}$ and NOx.

The above data used to plot graph of the emission and also the data collected through ESI[Tronic]. The graph shows the amount of gases emitted by Suzuki Swift with different norms, here we take BS III norms and BS IV norm engine to know the detail about how emission varies within both the engine. When the MAF is disconnected the ESI[Tronic] show the actual data of MAF as zero in system

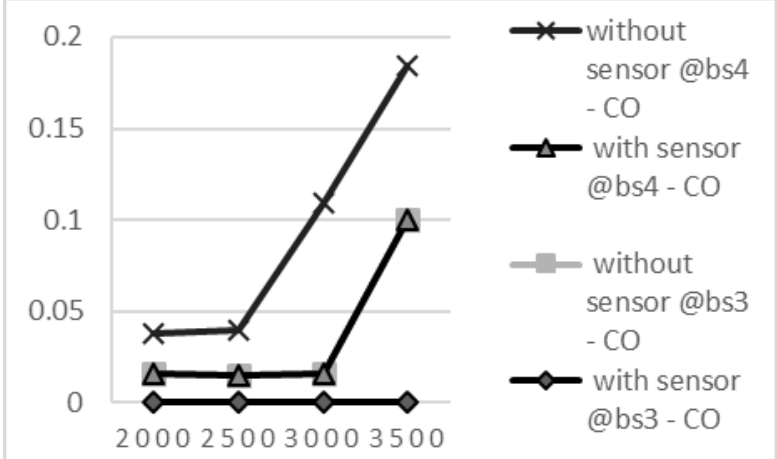

Fig 13: Emission of $\mathrm{CO}$ under the condition of with and without MAF sensor

This "Fig. 13" shows the amount of $\mathrm{CO}$ emitted in different RPM under the condition of MAF sensor connected and not connected, Carbon monoxide is a byproduct of combustion, present whenever fuel is burned in heterogenous mixture. During the connection of MAF the value of $\mathrm{CO}$ is completely zero and after the removal of MAF sensor the percentage of $\mathrm{CO}$ will increase up to $0.004 \%$ to

$0.100 \%$

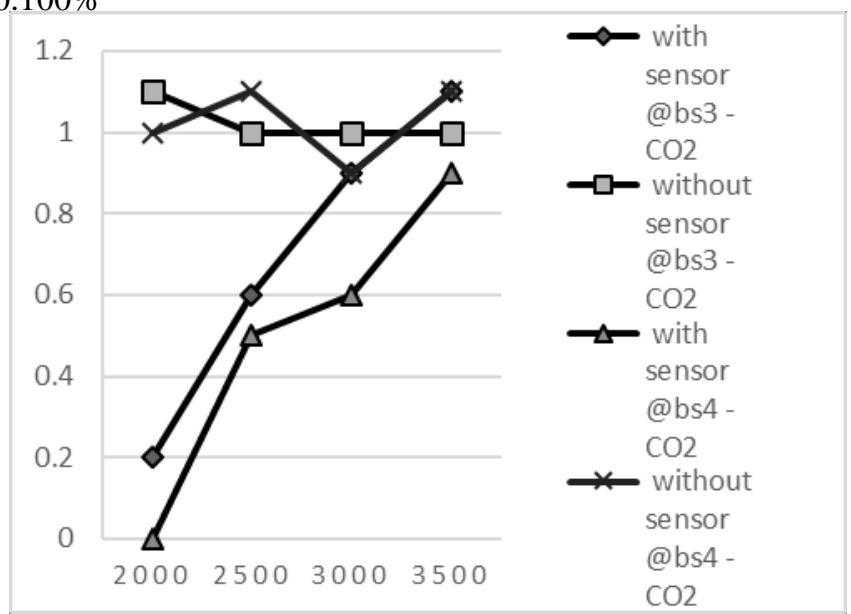

Fig 14: Emission of $\mathrm{CO}_{2}$ under the condition of with and without MAF sensor

This "Fig. 14" shows the amount of $\mathrm{CO}_{2}$ emitted in different RPM under the condition of MAF sensor connected and not connected, Carbon dioxide is formed from carbon monoxide during combustion. During the connection of MAF the value of $\mathrm{CO}_{2}$ from 0.20 to 4.0 and after the removal of MAF sensor the percentage of $\mathrm{CO}_{2}$ may reduce below 2.00 . 
The $\mathrm{CO}$ is converted into $\mathrm{CO}_{2}$ in lack of oxygen.

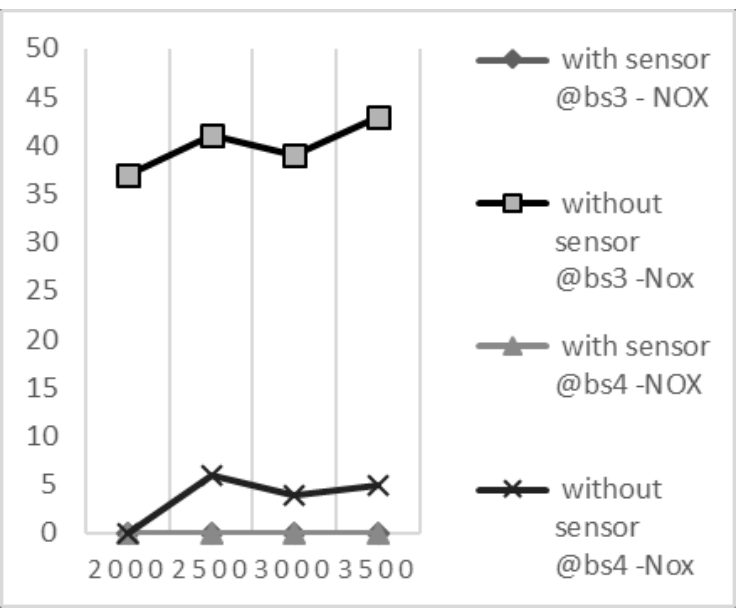

Fig 15: Emission of NOX under the condition of with and without MAF sensor

The "Fig. 15" shows the amount of NOX emitted during combustion. The NOX is the mixture of Nitrogen, Oxygen, and high enough temperatures. NOx emissions increase with higher combustion temperatures and lean mixture operation, which is when enough unreacted oxygen is present in the exhaust. The level of NOX is about $0 \%$ to $3 \%$ under the condition of MAF connection and it increased up to $30 \%$ to $50 \%$ in absence of MAF

\section{CONCLUSION}

This project work has provided an excellent opportunity and experience, to use our limited knowledge. Gained a lot of practical knowledge regarding, planning, searching, and using ESI[TRONIC] software and five gas analyzers while doing this project work. Project work is a good solution to get relationship between institution and industries. From the results of project emission, it is confirmed that due to failure of sensors the emission may change with great difference.

There is a huge difference in the results. The readings taken without the mass air flow sensor is very high. After the fitments of sensors, the output is highly varied, the gases shoed in the analyzer reduced rapidly and after a certain rpm.

Once the proper check of sensors as routine service of all the vehicles, the emissions will be reduced among the environment.

\section{REFERENCES}

1. Doru Baldean, and Adela-Ioana Borzan "Contributions on experimental research of fuel consumption and management system in K9K892 Diesel engine from Dacia Renault" MATEC Web of Conferences 184, 01018 (2018).

2. Ronith Stanly, Gopakumar Parameswaran, and R Rajkiran "Effect of Fuel System Choking on Vehicle Performance and Spray Field" SAE Technical Paper 2017-01-5017, 2017

3. Doru Baldean, MIlhai Aurel Crisan, and Adela Ioana Borzoan "contributions in Experimental Research concerning Diesel Fuel Supply and Lubrication in the case of comparative study between Euro V and IV common rail engines" CONAT 2016 Int Congress of Automotive and Transport Engineering pp 253-263.

4. Andrzej Sumorek, Marcin Buczaj "Problems of searching for failures and interpretation of error codes (DTCs) in modern vehicles" an international quarterly journal - 2016. Vol. 5. No. 3,27-34.
5. Olszowski "The methods of diagnosis of the innovatory management systems in car" Archives of Transport System Telematics Volume 3 • Issue 1 • February 2010.

6. Nekitsingh, A Khoodaruth "Investigation of the Benefits and Impact of Using the Hydrocarbon Refrigerant, HC-12a, in the Air Conditioning System of a Vehicle"

7. Adameic M Dziubinski, E Siemionek and A Drozd "Diagnostics of ABS and ESP system" IOP Conf Series: Materials Science and Engineering 421 (2018).

\section{AUTHORS PROFILE}

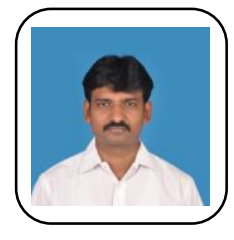

Dr. S. KARTHIKEYAN is working as Associate Professor in the Department of Automobile Engineering, Kalasalingam Academy of Education and Research, Virudhunagar District, Tamilnadu, India. He is currently doing active research in the area of Tribology of natural composite materials. His other areas of interest include characterization of materials and Supply Chain Management. 